\title{
Implicações do método em Gaston Bachelard ${ }^{1}$
}

Elyana Barbosa ${ }^{2}$

Gaston Bachelard é um "instaurador de discursividade". A concepção de tempo da Teoria da Relatividade Restrita de A. Einstein e o comportamento dos elementos infinitesimais da Mecânica Quântica (a microfísica) conduziram o saber para um novo campo de pensamento.

Bachelard coloca em questão conceitos entranhados no pensamento científico ocidental. Como pensar uma realidade sem substância? Como pensar um progresso descontínuo? O que é uma ruptura epistemológica? Como romper com a ideia de cumulatividade do saber? Como pensar a complementariedade rompendo com a Lógica Aristotélica e com a Dialética Hegeliana? E a continuidade e a multiplicidade temporais? É possível outra forma de racionalidade?

Ao fazer uma leitura cronológica das obras de Gaston Bachelard, percebi, neste pensador, três momentos na preocupação com o método de investigação. Um primeiro momento, inscrito nas suas análises e mostrado por ele mesmo, fala de um método mais objetivo possível, tanto na perspectiva epistemológica, como nas “imagens" da imaginação. Bachelard (1974, p.3) afirma que o método usado para falar dos elementos, o da prudência científica, foi insuficiente para fundamentar uma metafísica da imaginação.

No mesmo período no qual ele escreve livros de epistemologia, Bachelard escreve também livros sobre as imagens dos elementos (fogo, terra, ar e água) desejando ser o mais objetivo possível. Neste momento, o filósofo francês não estabelece diferença entre a linguagem discursiva e a linguagem poética, a ponto de afirmar que o Pensamento possui duas bordas, como um rio, uma que se esclarece pela imaginação e outra pela razão.

Em seu primeiro livro de epistemologia, a saber, Essai sur la connaissance approchée, Bachelard defende a tese do conhecimento aproximado. Aqui, ele se refere ao método como algo circunstancial que rapidamente é substituído por um método mais eficaz.

\footnotetext{
${ }^{1}$ Este trabalho é o resultado de várias reflexões que se originaram a partir do / Colóquio Bachelard Brasil - 2020.

${ }^{2}$ Professora da Pós-Graduação em Filosofia da Universidade Federal da Bahia - UFBA, Salvador. Endereço eletrônico: elyb@uol.com.br
} 
Nesta obra supracitada, Bachelard discorre suas ideias principais presentes em todos os livros de epistemologia. Sua tese sobre o conceito de "aproximação" (approchée), que é traduzido por "aproximado" nas edições brasileiras é na verdade circundar todo o objeto. Essa tese afirma que "[...] a descrição é a finalidade da ciência. É dela que se parte. É a ela que se volta $^{3 \prime \prime}($ BACHELARD, 1973b, p.14).

Assim, o autor postula para as análises epistemológicas o caráter sempre inacabado do conhecimento. O dado imediato "[...] é formado em oposição à reflexão" (BACHELARD, 1973b, p.18). Ele considera o conhecimento em seu refluxo, em seu movimento. Para Bachelard o real é inesgotável.

Ainda em Essai sur la connaissance approchée, o autor se refere à matemática como instrumento de dedução dos conhecimentos experimentais da Física e da Química contemporâneas. Conhecer e experimentar são os dois "motes" do pensamento científico. Cabe ressaltar que em seus livros de epistemologia ele pontua sempre as questões do conhecimento vinculado à experiência e seus impasses.

Também no Essai, chama-se a atenção para a importância do erro. Em relação ao conhecimento, o erro é mais importante do que a verdade, pois é ele que impulsiona o conhecimento para a verdade, esta é cristalizadora, só chegamos a ela testando o máximo possível os erros que aparecem na relação do conhecimento depois de inúmeras verificações. Segundo Bachelard (1973b, p.252), "o mundo é minha verificação5", a retificação infinita e necessária às descobertas atuais. "Em que situação um conhecimento aproximado é objetivo?6" Realidade e conhecimento possuem uma reciprocidade dinâmica.

O Essai é um livro de Teoria do Conhecimento que aborda críticas sobre o idealismo e o experimentalismo (os empirismos e os equívocos que o conhecimento imediato produz), fala da importância do detalhe no conhecimento e como ele dita a lei.

Para que exista conhecimento é preciso um sujeito cognoscente e um objeto a ser conhecido. "A aproximação é a objetivação inacabada, mas é uma objetivação prudente, fecunda, verdadeiramente racional, pois é ao mesmo tempo consciente da sua insuficiência e de

\footnotetext{
3 "(...) la description est, tout compte fait, la fin de la science. II faut en partir. II faut y revenir".

4 "(...) est formée justement en opposition avec la réflexion".

5 "Le monde est ma vérification".

6 "Dans quel sens peut-on dire qu'une connaissance approchée est objective?"
} 
seu progresso"” (BACHELARD, 1973b, p.300).

As considerações trazidas por Bachelard em Essai sur la connaissance approchée são fundamentais para que o novo espírito científico seja alicerçado em sua ideia primeira do conhecimento aproximado.

Na nossa leitura, a obra La philosophie du non é esclarecedora para compreendermos o que Bachelard propõe como novo espírito científico. Defendendo as bases do empirismo e do racionalismo ele propõe seu "racionalismo aplicado", um racionalismo prospector, diferente do racionalismo tradicional. Aparece também nesta obra a ideia de surracionalismo inspirando-se no movimento surrealista que então surgia como novidade no pensamento artístico de sua época.

Bachelard é, sem dúvida, o primeiro filósofo a inovar nas análises que faz da Mecânica Quântica, comparando os conceitos da física newtoniana a essa nova realidade, isto é, o real da microfísica. Com o aparecimento da mecânica quântica surge outro tipo de realidade que coloca em questão tudo o que se falava sobre os conceitos da Física clássica. A Física matemática contemporânea apresenta uma novidade sem precedentes na história.

Por meio de sua interpretação da Mecânica Quântica, ele faz uma análise do comportamento dos elementos microfísicos, isto é, os corpúsculos quânticos. A partir destes elementos infinitesimais sua análise de confronto com os elementos microfísicos, Bachelard coloca questões nunca antes abordadas. Com os novos conceitos, que se relacionam, mas não se negam, surge um novo campo de pressupostos.

Bachelard é um filósofo que cria conceitos e estes possuem uma significação própria dentro de sua epistemologia. Portanto, os conceitos bachelardianos são próprios, não são reelaborações de conceitos criados por outros filósofos, como os de Hegel ou Husserl, por exemplo. As noções bachelardianas só podem ser significadas no seu próprio pensamento.

Na análise das noções de tempo e de espaço, não apenas com base na Teoria da Relatividade de Einstein, mas também na Mecânica Quântica, Bachelard demonstra que esses conceitos mudam completamente de sentido em relação à Física Newtoniana. Além disso, o autor acentua para um novo modo de olhar para essas noções (entre outras) utilizadas pelos cientistas até então.

\footnotetext{
7 "L'approximation, c'est l'objectivation inachevée, mais c'est l'objectivation prudente, féconde, vraiment rationnelle puisqu'elle est à la fois consciente de son insuffisance et de son progrès".
}

Periódico Horizontes - USF - Itatiba, SP - Brasil - e021042 
Minha análise dos conceitos fundamentais do pensamento de Gaston Bachelard toma como ponto de partida seus argumentos elaborados no Essai. Trata-se de argumentos fundamentados em conceitos que percorrem todas as suas obras epistemológicas, isto é, até a obra Le matérialisme rationnel. Na obra La philosophie du non o autor melhor desenvolve os seus principais conceitos, já lançados no Essai, por exemplo.

Le nouvel esprit scientifique, de 1934, e La philosophie de non, de 1940, são dois livros que se complementam mutuamente. Considero que esta segunda obra Bachelard explica com mais rigor o novo espírito científico ao enunciar a essência do seu "racionalismo aplicado" e sua noção de dialética. Nestes dois livros, ele faz uma análise da Física contemporânea, que é seu ponto de partida para evidenciar as ideias de sua epistemologia. Então, é necessário, numa leitura sistemática para compreender sua noção de novo espírito científico, partir da obra de 1940 na qual ele prepara um ensaio na perspectiva de esclarecer o que é a nova realidade epistêmica do século XX, já demonstrada na obra de 1934.

Em Le nouvel esprit scientifique, Bachelard aponta para o "limite" de certas teorias como as dedutivas a partir de Descartes e o conceito de adequação e o empirismo "tout cours" que até então eram vistas como teorias opostas (matemática e experiência). A ligação da nova Física com a álgebra revela uma "aproximação" inédita que faz a História da física revelar outra problemática (Newton e Einstein). São dois paradigmas diferentes e, assim, o campo axiomático muda completamente. Contudo, essas duas bases de pensamento não se excluem, mas se complementam quando pensadas mediante uma filosofia do não.

O não de Bachelard não é negação, mas diferença, na medida em que aponta os limites. Portanto, não é negar mediante exclusão. Cabe notar que muitos intérpretes confundem o não de Bachelard. Não se trata do não (aufheben) que é afirmação (uma nova tese) e superação ao mesmo tempo. O não de Bachelard é diferença e se fundamenta na ideia de força.

A ideia de negação bachelardiana contraria, nesse sentido, o da dialética hegeliana. 0 não em Bachelard não é um pensamento negativo, é distinção, exceção, detalhe. Iguala-se ao pensamento nietzschiano. "Super homem" (übermench) contra quem? O na negação dialética de Bachelard, sua lógica é a dos contrários e não dos contraditórios, verdade / falsidade, e sim Verdade e verdade, Falso, falso.

Como já dissemos, o seu livro La philosophie du non - Essai d'une philosophie du nouvel 
esprit scientifique é um amadurecimento do pensador em relação ao Le nouvel esprit scientifique escrito em 1934. O que interessante notar é que entre um e outro se passaram seis anos, tempo em que o autor amadurecia o seu pensamento epistemológico.

Durante esse período escreveu La Formation d'esprit scientifique onde ele aconselha aos seus leitores sobre a necessidade de superar os obstáculos epistemológicos no sentido de melhor compreender o desenvolvimento do saber científico em relação à sua atualidade.

Para que se possa conquistar a objetividade é preciso conhecer, por meio da História das Ciências, os fatores que impedem o seu desenvolvimento. "A era do novo espírito científico se inicia no momento em que a relatividade einsteiniana deforma conceitos primordiais em que acreditavam ser imutáveis" ${ }^{81}$ (BACHELARD, 1977b, p.7).

Segundo Bachelard (1977b), os obstáculos epistemológicos aparecem no ato do conhecimento. "Quando se procuram as condições psicológicas do progresso da ciência, logo se chega à convicção de que é em termos de obstáculos que o problema do conhecimento científico deve ser colocado"' (p.13).

Há os obstáculos externos relacionados à complexidade e à fugacidade que são próprios dos fenômenos, e também da fragilidade dos sentidos. Contudo, a noção de obstáculos epistemológicos não se refere às coisas externas, na medida em que esses obstáculos acompanham sempre o ato do conhecer. É por esse motivo que Bachelard os trata como condições psicológicas que interferem na conquista da objetividade.

Os obstáculos destacados em La formation de l'esprit scientifique são: a experiência primeira como correlata ao conhecimento comum. Bachelard, em todos os seus livros que versa acerca da epistemologia, chama a atenção para a necessidade de romper com o senso comum. Para ele, a ruptura epistemológica entre senso comum e saber científico passa a ser um instante do método.

Nessa obra de 1938 o autor também chama a atenção para o perigo do conhecimento geral, considerado como um grande obstáculo. A generalização que teve vigência de Aristóteles a Bacon e que ainda permanece em alguns saberes (BACHELARD, 1977b). O obstáculo verbal, o

\footnotetext{
8 "L'ère du nouvel esprit scientifique en 1905, au moment où la Relativité einsteinienne vient déformer des concepts primordiaux que l'on croyait à jamais immobiles".

9 "Quand on cherche les conditions psychologiques des progrès de la science, on arrive bientôt à cette conviction que c'est en termes d'obstacles qu'il faut poser le problème de la connaissance scientifique".
} 
substancialismo (acreditar que os fenômenos têm sempre uma substância, um qüid, que os torna objetivo), o conhecimento unitário e pragmático, o obstáculo animista e o conhecimento quantitativo.

Para o filósofo francês, é preciso que o cientista, para fazer parte de uma "cidade científica", elabore uma catarse dos erros do antigo espírito científico, com a finalidade de superar os obstáculos epistemológicos, ou seja, superar tomando consciência da existência das ideias-obstáculos ao progresso do saber.

Para Bachelard (1977b), a "observação" que parte dos sentidos não assegura a verdade. A história da ciência, a física matemática e a química matemática (duas ciências bem constituídas porque têm uma história) e que só podem ser analisadas através da sua história. As implicações do método, partindo dessas duas ciências (a teoria da relatividade e a mecânica quântica) apontam para uma nova concepção de real (res).

As principais regras metodológicas apresentadas que aparecem em La formation de l'esprit scientifique são: 1) romper com o senso comum como crítica ao conhecimento imediato. 2) A sua crítica ao empirismo "tout court", isto é, a um empirismo ingênuo que antecedeu ao seu pensamento, agora trata-se sim de um "racionalismo aplicado" proposto por ele.

De 1928 a 1953 G. Bachelard vai significando de um modo mais claro seus conceitos filosóficos. Para a sua época, Bachelard é de uma grande ousadia, na medida em que contraria filósofos e cientistas. No entanto, quando o filósofo francês critica esses pensadores ele o faz em debate com suas ideias.

Em outras palavras, durante vinte e nove anos de escrita epistemológica, ao escrever, ele esclarece melhor os seus conceitos, como o de ruptura (instante do método quando é preciso romper com o saber do senso comum e o saber imediato), objetividade - objetivação, racionalismo aplicado - racionalismo e empirismo, fenomenotécnica - fenômeno - técnica, surracionalismo - surrealismo, dialetização - dialética.

Os conceitos criados por Bachelard só têm sentido em seu pensamento. Não se tratam, portanto, de apropriações de significações de outros pensadores. O princípio da identidade da Lógica Formal Aristotélica é substituído pelo não que é diferença. No novo espírito científico, a contradição hegeliana é contestada diante na física dos elementos infinitesimais ao apresentar um novo estatuto ontológico do objeto do conhecimento. 
Assim, é possível as considerações da fenomenologia de Husserl acerca da noção de fenômeno são contestadas por Bachelard dizer que o pensamento de Gaston Bachelard é singular, não tem antecessores. Ele vai apresentar o novo espírito científico por meio de conceitos antes nunca empregados.

A Mecânica Quântica, Física dos elementos infinitesimais, leva Bachelard a uma análise do comportamento desses elementos, surge então outro modo de ver os fenômenos, que não podem ser comparados aos fenômenos da realidade comum que são coisas (res), pois estes têm como características a questão da origem, da temporalidade, da espacialidade independente do tempo. Os elementos infinitesimais não respondem a essas questões. No objeto infinitesimal o tempo passa a ser uma dimensão dos fenômenos: comprimento, largura, espessura e tempo. Essa análise leva a pensar nos fenômenos com temporalidades diferentes. Foucault se refere a duas temporalidades justapostas a do sujeito que observa e a do fenômeno que é observado. Com a concepção newtoniana de tempo absoluto era impossível pensar desse modo, apontando assim para os limites dos conceitos clássicos. Apontar para os limites de uma determinada teoria é mostrar os seus erros buscando-os na história da ciência sob a luz da ciência mais atual.

Eis então em Bachelard o conceito de recorrência histórica, que significa partir da atualidade para analisar o passado da ciência através da significação conceitual. O conceito de tempo relativo não pode ser analisado como uma continuação do conceito de tempo em Newton. Por isso motivo Bachelard apresenta a ideia segundo a qual os conceitos são dinamológicos. A significação é dada na análise histórica das ciências.

[...] só a matemática como um pensamento que possui uma linguagem simbólica, inventiva, trabalha com conceitos dinamológicos, conceitos que acompanham o movimento dialético dos fenômenos [...] a linguagem cotidiana é condicionante, pois já está estabelecida, já está codificada. É preciso usar um tipo de linguagem que se adapte ao movimento, à mudança, por isso há necessidade de a ciência trabalhar com a linguagem simbólica (BARBOSA, 1996, p.52).

Para entender o que Bachelard denomina de "conhecimento aproximado" (os juízos matemáticos relacionados à experiência o que mais tarde ele vai denominar de racionalismo aplicado) é preciso perceber a importância do conceito. $O$ trabalho com a significação conceitual é importante na medida em que é preciso saber quando o conceito é vazio, quando não se aplica 
mais a determinados eventos.

O conceito de "real" como res (coisa) com características gerais só se aplica até a Teoria da Relatividade de Einstein e o advento de Mecânica Quântica, quando o tempo perde a significação de absoluto (diz-se, o real está no tempo) e passa a ser uma dimensão do objeto. Os conceitos da Física passam para outra significação. Esta nova perspectiva do tempo possibilita pensar em "realidades justapostas", temporalidades diferentes.

Trata-se de uma verdadeira revolução na concepção de tempo como linearidade, como origem (quando?) como cumulatividade. O tempo Einsteiniano permite pensar em "descontinuidade", em "ruptura", conceitos ligados ao ato de conhecer e não como propriedade do ser.

Os historiadores do conhecimento científico passam a ter um novo ponto de partida, não mais a cumulatividade do passado, mas, pensar a história a partir do presente, da atualidade do conceito com as suas significações atuais, do presente para o passado. Portanto, a história precisa ser reescrita, ressignificada. Ela deve partir do presente para "julgar" o passado.

Em Le matérialisme rationnel, Bachelard se despede dos seus escritos epistemológicos esclarecendo quais são as matérias da razão e quais as matérias da imaginação. Na sua obra $L a$ poétique de l'espace, ele revoluciona o seu pensar sobre o método. Não mais a razão nem a experiência. Agora uma imaginação criadora que parte da contemplação e da observação, "a imagem numa consciência individual, para ajudar-nos a restituir a subjetividade das imagens e a medir a amplitude, a força, o sentido da transubjetividade da imagem ${ }^{10 " \prime}$ (BACHELARD, 1974 p.36).

O método fenomenológico em Bachelard tem uma significação própria, ele é o da imaginação criadora. Trata-se de um método de uma imagem nova. Contrapondo à Husserl, podemos perceber que não é um método descritivo, mais um método da imaginação criadora.

Segundo Bachelard (1968), o método fenomenológico permite a identificação do sujeito com o objeto, entre o sujeito e o objeto não há mediação (em Husserl, na consciência existe uma parte material (Hylé) que permeia esta relação). O método fenomenológico de Bachelard é o da imaginação criadora. Segundo ele, a imaginação ultrapassa a realidade, ela vê o invisível, ela vai ao fundo das coisas (BACHELARD, 1974).

\footnotetext{
10 "(...) l'image dans une conscience individuelle - peut nous aider à restituer la subjectivité des images et à mesurer l'ampleur, la force, le sens de la transsubjectivité de l'image".
} 
Se analisarmos a obra bachelardiana cronologicamente, percebemos que o autor nos leva para um caminho que corresponde ao da sua existência. Ele a inicia buscando um método o mais objetivo possível, tanto na sua análise epistemológica como na sua análise das imagens dos elementos até atingir uma liberdade total na sua poética, onde ele alcança um ponto sem compromisso com nada de material, de concreto até atingir "as asas da imaginação".

\section{Referências}

BACHELARD, G. La poétique de la rêverie. Paris: PUF, 1968.

BACHELARD, G. Le matérialisme rationnel. Paris: PUF, 1973a.

BACHELARD, G. Essai sur la connaissance approchée. Paris: Vrin, 1973b.

BACHELARD, G. La poétique de l'espace. Paris: PUF, 1974.

BACHELARD, G. La philosophie du non (essai d'une philosophie de l'esprit scientifique). Paris: PUF, 1975.

BACHELARD, G. Le nouvel esprit scientifique. Paris: PUF, 1977a.

BACHELARD, G. La formation de l'esprit scientifique. Paris: Vrin, 1977b.

BARBOSA, E. Gaston Bachelard: o arauto da pós-modernidade. Salvador: EDUFBA, 1996. 